\title{
A poptosis and Phagocytosis Activity of M acrophages Infected by Mycobacterium tuberculosis Resistant and Sensitive Isoniazid Clinical Isolates
}

\author{
Farida J. Rachmawaty', Tri Wibawa', and M arsetyawan H .N .E. Soesatyo' \\ Graduate School of Tropical Medicine, Gadjah Mada University School of Medicine, \\ Yogyakarta55281, Indonesia. \\ Department of Microbiology, Gadjah Mada University School of Medicine, Yogyakarta 55281, \\ Indonesia. \\ Department of Histology and Cell Biology, Gadjah Mada University School of Medicine, \\ Yogyakarta55281, Indonesia.
}

\begin{abstract}
M ycobacterium tuberculosis (M.tb) is the main causative pathogen that cause the pulmonary tuberculosis. Intracellular M tb was reported ableto induce macrophages apoptosis, which may havecrucial rolein the regulation of immun response against $M$.tb infection. As an intracellular bacteria, $M$.tb able to live and replicate within macrophages. Phagocytosis is the first step to achieved this condition. The induction of macrophages apoptosis by INH resistant and sensitive M .tb clinical isolates, and H37Rv was studied. The macrophages apoptosis level were measured using an Ag-capture ELISA for histone and fragmented DNA (Cell Death Detection ELISA Diagnostic GmBH). Phagocytosis activity al so analyzed, after staining using fluorescencedye (A crifluorm, Scientific Device Lab.). The results showed that there was no significantly different between IN H resistant and sensitive $M$.tb clinical isolates in respect their ability to induce apoptosis. The phagocytosis activity among the clinical isolates was shown to be strain dependent, and undistinguishable between the $M$ tb clinical isolates. There was no association between macrophages apoptosis level and the phagocytosis activity. These data suggested that among the virulent M tb clinical isolates, theability to induce macrophages apoptosis and phagocytosis were consistently in comparable level
\end{abstract}

Keywords: M ycobacterium tuberculosis, apoptosis, phagocytosis, macrophages, isoniazid

\section{Introduction}

$M$ ycobacterium tuberculosis ( $M . t b)$, the main causative pathogen of tuberculosis (TB), is responsible for eight million incidences of TB and killing more than 1.7 million peoples per year worldwide (WHO, 2005). TB asworld's health problem becomes morecomplicated as themulti drug resistant (MDR) TB occurs, especially to isoniazid

*Corresponding author: Tri Wibawa, Department of Microbiology, Gadjah Mada University School of Medicine, Yogyakarta 55281, Indonesia. Phone: +62274-6492458; Fax: +62-274-581876; E-mail: twibawa@ugm.ac.id
(INH) and rifampicin (WHO, 2004).

INH is powerful and most widely used among anti-tuberculosis drugs, which interferes with nearly every metabolic pathway in M .tb (Zhang, 2004). Therewasno agreement among the scientist about the target molecule of INH in killing the $\mathrm{M}$.tb. However, accumulated data suggested strongly that mycolic acid synthesis selectively inhibited by INH and correlated with their lethal effect (Slayden and Barry, 2000). There is a correlation between inhibition of mycolic acid synthesis and $M$.tb viability (Takayama et al., 1978).

$M$.tb is an intracellular microbe which 
abletoliveand replicatein themacrophages, which was defined its pathogenocity. These process is start from the phagocytosis event. A mannose-containing lipoglycan of the $M$.tb cell wall, theterminal mannose-capped lipoarabinomannan (ManLAM), has been implicated in the regulation of several of these processes. The presence of ManLAM on the mycobacterial surface places this molecule in an ideal position to mediate the initial interactions between $M$.tb and macrophages, which in turn facilitates the phagocytosis (Hunter and Brennan, 1990; Kanget al., 2005)

M.tb infection could induce human alveolar macrophages and monocytesmacrophages apoptosis (Keane et al., 1997; Klingler et al., 1997; Placido et al., 1997). There is an inverse correlation between mycobacterial virulence with infected macrophages apoptosis level. Virulent $M$.tb induces little apoptosis as compare to attenuated strains (Keane et al., 2000). Macrophages apoptosis has direct correlation with killing of intracellular bacilli (Molloy et al., 1994; Oddo et al., 1998). A poptosis of the macrophages is crucial for innate immunity against $M$.tb and eradication of intracellular $M$.tb.

Previous reports showed that the $M$.tb cell wall is very important in its pathogenicities. Furthermore, the accumulated data suggested that IN H target molecule reside in the cell wall, apoptosis were induced by component of the cell wall, and the phagocytosis also was facilitated by the component of cell wall. It is also reported that the disturbance of mycolic acid biosynthesis may resulted in the disturbance of $M$.tb cell wall structure. The aim of this work is to study the induction of macrophages apoptosis by $M$.tb resistant and sensitive INH clinical isolates. Furthermore, the association between the apoptosis level and phagocytosis activity of themacrophages was explored.

\section{M aterials and M ethods Mycobacterium tuberculosis clinical isolates.}

M.tb isolates were obtained from patients attend to the primary health care centers in Yogyakarta. The M.tb were cultured on Lõwenstein-Jensen (LJ) medium. Sensitivity of the M.tb clinical isolates to INH were tested using the agar proportional method on LJ medium (Freixo et al., 2002). INH sensitivity weretested with concentrations of $0.1 \mathrm{mg} / \mathrm{ml}$ and $1 \mathrm{mg} / \mathrm{ml}$. Thecolonies of the $M$.tb wereonly observed after 3 weeks incubation on $L J$ medium. Two INH resistant $M$.tb clinical isolates (RI and $\mathrm{R} 2$ ) and two INH sensitive $\mathrm{M}$.tb clinical isolates (S1 and S2) were chosen for further analysisin thiswork.

\section{Primary culture of macrophages derived from peripheral blood}

Peripheral blood mononuclear cells were isolated using standard gradient centrifugation method of $\mathrm{Histopaque}$ (Sigma Diagnostic Inc.) from heparintreated blood of healthy and non-smoker donors after informed consent weregranted. Mononuclear cells were suspended with complete medium which was consist of RPMI 1640 supplemented with L-glutamine, without sodium bicarbonate (GIBCO), 10\% fetal bovine serum (Invitrogen Corp.), antifungal, and antibiotics. The cells were plated in polystyrene tissue culture disc ( $\mathrm{NunC}^{\mathrm{m}}$ ) and then incubated for $2 \mathrm{~h}$ at $37^{\circ} \mathrm{C}$ with $5 \% \mathrm{CO}_{2}$. After incubation, non-adherent cells were removed by three times washing with RPMI 1640. Adherent monocytes were collected by vigorous pippeting and subjected for viability test and cell counting after trypan blue staining. Freshly isolated monocytes were suspended in complete medium and replated to the 24 wells polystyrene tissue culture disc at a concentration of $5 \times 10 / \mathrm{ml}$ and incubated at 
$37^{\circ} \mathrm{C}$ with $5 \% \mathrm{CO}_{2}$. The cells wereready to be infected at the fourth Intracellular $M$.tb counting was performed at 200 microscope fields (400 time magnificence). The data were collected from five independent experiments and showed as means with standard error means(SEM).

Previously, significantly different phagocytosis level were reported by Schlesinger (1993) between virulent and avirulent mycobacteria. Our data showed that phagocytosis level were undistinguishable between virulent $M$.tb strains.

The association between macrophages apoptosislevel and thephagocytosisactivity weremeasured using Spearman'stest. It was observed a negative association between the two variables. The $M$.tb clinical isolates that phagocytosed easier (more intracellular M.tb) seemed induce less apoptosis to the macrophages, though this phenomenon was notstatistically significant $(P>0.05)$.

\section{Conclusion}

$M$.tb clinical isolates were able to induce the macrophages apoptosis in vitro. The ability of $M$.tb virulent strains to induce macrophages apoptosis was not attributed with its sensitivity to isoniazid. There was also no significantly difference between INH-resistant and sensitive $\mathrm{M}$.tb in respect with its phagocytosis into the macrophages. Negative association between level of apoptosis and level of phagocytosis activity wasnot significantly observed in thiswork.

\section{Acknowledgment}

This work was partly funded by The Ministry of Research and Technology, Republic of Indonesia through Riset Unggulan Terpadu X (RUT X) grant awarded toT.W.

\section{References}

Freixo, I.M., Caldas, P.C.S., Martins, F., Brito, R.C., Ferreira, R.M.C., Fonseca, L.S. and Saad, M.H.F., 2002. Evaluation of Etest strips for rapid susceptibility testing of M ycobacterium tuberculosis. J. Clin. M icrobiol ., 40, 2282-2284.

Hunter, S.W., and Brennan, P.J., 1990. Evidence for the presence of a phosphatidylinositol anchor on the lipoarabinomannan and lipomannan of $M$ ycobacterium tuberculosis. J. Biol. Chem., 265, 9272-9279.

Kang, P.B., Azad, A.K.,Torrelles, J.B., Kaufman, T.M., Beharka, A., Tibesar, E., Deslardin, L.E., and Schlesinger, L.S., 2005. The human macrophage mannose receptor directs M y cobacterium tuberculosis lipoarabinomannan-mediated phagosome biogenesis. J. Exp. Med., 202, 987-999.

Keane, J., Balcewicz-Sablinska, M.K., Remold, H.G., Chupp, G.L., Meek, B.B., Fenton, M.J., and Kornfeld, H., 1997. Infection by $M$ ycobacterium tuberculosis promotes human alveolar macrophage apoptosis. In fect. Immun., 65, 298-304.

Keane, J., Remold, H.G., and Kornfeld, H., 2000. Virulent M ycobacterium tuberculosis strains evade apoptosis of infected alveolar macrophages, J. Immunol., 164, 2016-2020.

Klingler, K., Tchou-Wong, K.M., Brandli, O., Aston, C., Kim, R., Chi, C., and Rom, W.N., 1997. Effect of mycobacteria on regulation of apoptosis in mononuclear phagocytes. Infect. Immun. 65, 5272-5278.

Molloy, A., Laochumroonvorapong, P., and Kaplan, G., 1994. Apoptosis, but not necrosis, of infected monocytes is coupled with killing of intracellular bacillus Calmette-Guerin. J. Exp. M ed. 180, 1499-1509. 
Oddo, M., Renno, T., Attinger, A., Bakker, T., MacDonald, H.R., and Meylan, P.R.A., 1998. Fas ligand-induced apoptosis of infected human macrophages reduces the viability of intracellar M ycobacterium tuberculosis. J. I mmunol., 160, 5448-5454.

Placido, R., Mancino, G., Amendola, A., Mariani, F., Vendetti, S., Piacentini, M., Sanduzzi, A., Bocchino, M.L., Zembala, M., and Colizzi, V., 1997. A poptosis of human monocytes/macrophages in $M$ ycobacterium tuberculosis infection. J. Pathol., 181, 31-38.

Schlesinger, L.S., 1993. Macrophages phagocytosis of virulent but not attenuated strain of $M$. tuberculosis is mediated by mannose receptors in addition to complement receptors. J. Immunol., 2, 659-669.

Slayden, R.A., and Barry, C.E., 2000, The genetics and biochemistry of $\mathrm{INH}$ resistance in $M$. tuberculosis. M icrob. Infect., 2, 659-669.

Stokes, R.W., N orris-Jones, R., Brooks, D.E., Beveridge, T.J., Doxsee, D., and Thorson, L.M., 2004. The glycan-rich outer layer of the cell wall of $M$ ycobacterium tuberculosis acts as an antiphagocytic capsule limiting the association of the bacterium with macrophages. Infect. I mmun., 72, 56765686.

Takayama, K., Wang, L., and David, H.L., 1972. Effect of Isoniazid on the in vivo mycolic acid synthesis, cell growth, viability of $M$ ycobacterium tuberculosis. A ntimicrob A gents Chemother., 2, 29-35.

WHO. (2004). Anti-tuberculosis drug resistance in the world: Third global report, The WHO/IUATLD Global Project on Anti-tuberculosis Drug Resistance Surveillance, WHO/ HTM/ TB/ 2004.343.
WHO. (2005). Global tuberculosis control: surveillance, planning, financing. W HO report 2005 . Geneva, WHO/ HTM/ TB/ 2005.349.

Zhang, Y., 2004. Isoniazid, In: Rom WN and Garay ST eds. Tuberculosis 2 ed., Lippincott Williams \& Wilkins, Philadelpia, pp: 739-758. 